\title{
Processing of Magnesium-Based Metal Matrix Nanocomposites by Ultrasound-Assisted Particle Dispersion: A Review
}

\author{
Hajo Dieringa \\ Helmholtz-Zentrum Geesthacht, MagIC—Magnesium Innovation Centre, Max-Planck-Str. 1, \\ 21502 Geesthacht, Germany; hajo.dieringa@hzg.de; Tel.: +40-4152-871-955
}

Received: 9 April 2018; Accepted: 4 June 2018; Published: 7 June 2018

\begin{abstract}
Magnesium-based metal matrix nanocomposites (MMNCs) are an important topic in the development of lightweight structural materials, because their optimized properties are of great interest to the automotive and aerospace industries. Moreover, components with functional properties will also be manufactured from Mg-MMNCs in the future. With a large surface to volume ratio, nanoparticles in the magnesium matrix have an immense effect on mechanical properties, even at low concentrations. The mechanical properties of these materials can be tailored using ceramic nanoparticles, which have been available at a very low cost for a number of years. However, the particle concentration, chemical composition, particle size, and process parameters must be attuned to the respective alloy, in order to influence the resulting properties. When using very small particles, a major problem is to homogeneously distribute the particles in the melt. Due to their large surface area, strong van der Waals forces act to hold the particles together in clusters. At the same time, wettability of the particles with a magnesium melt is very poor. Ultrasonic stirring processes have proven their effectiveness in the de-agglomeration and dispersion of nanoparticles. This review presents ultrasound-assisted processes for the production of these materials and describes some properties of the resulting Mg-MMNCs.
\end{abstract}

Keywords: metal matrix nanocomposites; ultrasound; magnesium alloy; ceramic nanoparticle

\section{Introduction}

The use of magnesium alloys has steadily increased over the last twenty-five years in the automotive industry and $3 \mathrm{C}$ (computer, communications, and consumer electronics). Magnesium alloys for room temperature applications, such as AZ91, AM50, and AM60, give excellent room temperature strength and ductility, they are easily castable, have good machinability, and their corrosion resistance is fairly good. When it comes to higher temperatures, more advanced alloys containing rare earth elements (AE42, AE44) [1], silicon (AS21, AS41) [2], strontium (AJ62) [3], barium (DieMag422) [4], and other more costly elements are also in use. All these alloys contain aluminium as the alloying element, because for high pressure die casting (HPDC) it is necessary to maintain a large solidification interval (the gap between solidus and liquidus). For sand casting or low-pressure die casting, aluminium-free alloys that contain yttrium and rare earth elements (WE43) or silver and rare earth elements (QE22) are used, and there are newly-developed alloys that contain tin and calcium (Mg-Sn-Ca system) [5]. During solidification, these alloying elements form stable precipitates with $\mathrm{Mg}$ or Al, which endow good creep resistance and high temperature strength. As early as the 1960s, metal matrix composites with microparticles, short or long fibres, and whiskers were developed, manufactured with volume contents of up to $50 \%$ of reinforcement. The mechanical properties of 
the base alloys have been considerably improved by reinforcement. Due to their high reinforcement content, however, the density of composites significantly increased.

To improve the properties of all the alloys mentioned, yet keep their density low, ceramic nanoparticles can be added to the melt, during or before casting, in order to influence the microstructure. With regard to additions of ceramic particles or fibres, which are added to metallic matrices to strengthen the matrix by Orowan strengthening or by (Hall-Petch) grain boundary strengthening, several processes can help to distribute the reinforcements in the melt. In addition to melt shearing, ultrasonic treatment (UST) is another way to disperse the particles effectively. Ceramic nanoparticles tend to agglomerate in molten metals due to their large surface energy. Further, the wetting of a magnesium melt on the ceramic surfaces of the particles can be poor. With ultrasonic treatment the agglomerates can be broken up and particles are distributed more evenly in the melt. Ultrasonic treatment of a magnesium alloy's melt activates several different effects that will be briefly described at the beginning.

\subsection{Ultrasound Equipment}

A large number of ultrasonic generators, transducers, and acoustic horn materials and forms are available for the ultrasonic treatment of molten metals. Typically, either piezoceramic or magnetostrictive transducers are used. The former are temperature-sensitive and must, therefore, be cooled or be kept sufficiently apart from the melt, which can be achieved by using a long horn. These devices are able to keep the amplitude of the generated ultrasound constant. This can become a problem if, for example, the resonance frequency changes due to the use of a horn in a hot metal melt. The reason for this is a change in the Young's modulus as a function of temperature and the expansion of the material. Magnetostrictive transducers consist of a series of magnetostrictive plates that are water-cooled. This means there is no risk of overheating for these devices. Their design is also capable of compensating for temperature-related changes in the resonance frequency of the horn. The controller for magnetostrictive ultrasound transducers is able to compensate for changes in the resonance of the entire system by amending the frequency. This makes them more robust than piezoceramic systems.

An extension and a sonotrode are generally added to the acoustic transducer. If necessary, a booster can also be added between them. As already mentioned, the resonance frequency depends on the Young's modulus of the acoustic horn material. Equation (1) describes the relationship between the wavelength $\lambda$, the speed of sound $c$ and the resonance frequency $f$. The density $\rho$ and the Young's modulus $E$ are included in the equation as material properties:

$$
\lambda=\frac{C}{f}=\frac{1}{f} \sqrt{\frac{E}{\rho}} .
$$

A more detailed description of the calculation possibilities for sonotrodes and amplifiers is given in [6].

When selecting a suitable sonotrode material for magnesium melts, it is always necessary to strike a balance between conflicting demands. The material should have a high melting point and low solubility in a magnesium melt. Moreover, a low thermal expansion and low temperature dependence of the Young's modulus are advantageous. In industrial applications, high fatigue strength and low sensitivity to thermal cycling are also required [6]. Niobium and titanium are usually used for magnesium alloy sonification. The advantage of niobium is the small variation of its Young's modulus as a function of temperature and its high melting point. Titanium, on the other hand, is very stable in a magnesium melt and it is almost insoluble. In our experiments with steels as the sonotrode material, it showed these are unsuitable, because immediate erosion of the sonotrode surface occurs, as can be seen in Figure 1. 


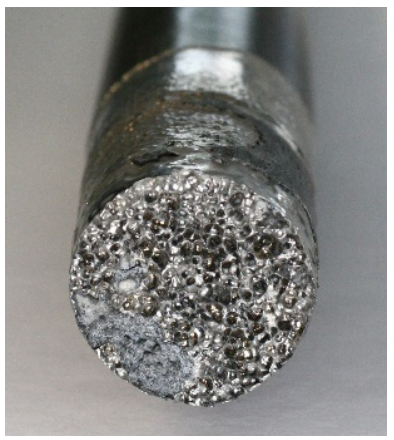

Figure 1. Surface erosion of a steel sonotrode, diameter: $35 \mathrm{~mm}$.

\subsection{Cavitation}

During UST a certain area of the melt below the sonotrode receives alternating compression and expansion with the frequency of the ultrasound (US). When undergoing expansion, the local stress in the liquid may be larger than the attracting forces between the atoms or molecules. During this brief period of expansion, cavities form that are called cavitation bubbles. Temperatures in ranges of several thousand degrees and pressures up to a thousand atmospheres can be created during the short life of a collapsing cavitation bubble [7]. It makes these hot spots suitable for physical and chemical reactivity.

When impurities are distributed in the melt, the attracting forces between the atoms of a liquid are less homogeneous and, therefore, significantly decreased. The surface of these impurities may contain notches where gas is enclosed. The addition of agglomerated ceramic nanoparticles will also include gas entrapments. At the interface between these impurities and located in small caverns between their surfaces the gas may already exist and this is where cavitation tends to occur. When these gas bubbles explode, the forces acting on the surrounding particles may be greater than the van der Waals force agglomerating the particles. This is the moment when the clusters are destroyed by cavitation.

Bubbles may accumulate and become larger, by absorbing dissolved gases from the melt as well. When they become large enough, these bubbles may rise to the surface of the melt, this process is called degassing [8]. Eskin describes different types of cavities [9], which are:

- Cavities that pulsate and keep the content of vapour gas constant.

- Cavities that grow during pulsation, due to tensile stresses and diffusion of the gas only into the cavity.

- Cavities that collapse under compressive stresses, producing plenty of small cavities and massive local pressure.

Figure 2a illustrates growth of cavitation bubbles in a metallic melt and their collapse, induced by ultrasound. Figure $2 \mathrm{~b}$ shows a cluster of nanoparticles in a magnesium melt that contain a gas entrapment. Cavitation is generated under the ultrasonic horn, which can cause the gas bubble to explode, as shown in Figure 2a. The cluster is destroyed and broken down into smaller clusters or even to individual nanoparticles.

The repeated formation and collapse of hundreds or thousands of cavities produces shock waves in the melt that influence its capability not only to dissolve gases, but also to overcome the attracting forces of nanoparticle agglomerates and to break down the initial growth of solidified branches of dendrites when the temperature has reached the liquidus. 


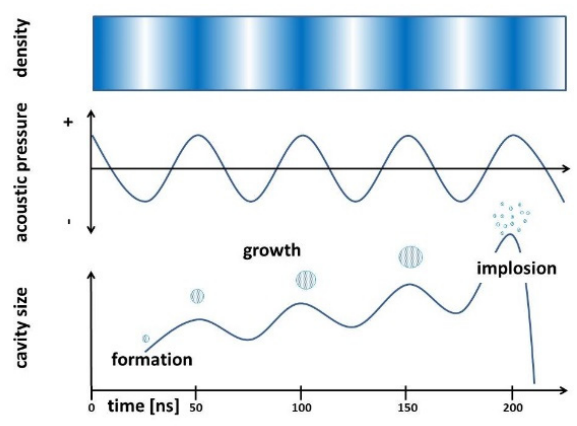

(a)

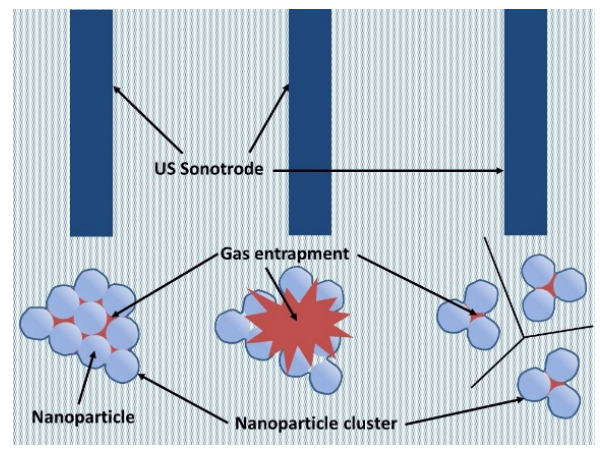

(b)

Figure 2. (a) Development of a cavity and its growth, dependent on the acoustic pressure induced by ultrasound (based on Figure 1 in [10]); and (b) a cluster of nanoparticles that is destroyed by the cavitation of the entrapped gas under the sonotrode and, thus, distributed into several smaller clusters.

\subsection{Acoustic Streaming}

UST causes a macroscopic flow of the melt. The quantity of this streaming depends heavily on the ultrasound intensity, melt viscosity and therefore melt temperature, mould geometry, and the ability of the melt to absorb sound. Eskin distinguishes between three different types of acoustic flow or acoustic streaming [9]. Firstly, the flow named after Hermann Schlichting, a student of Ludwig Prandtl. It occurs close to boundary or phases interfaces. These interfaces are thought to contain cavitation bubbles, which oscillate and create the Schlichting flow. Heat and mass transport is significant in this type of flow. The second type of acoustic streaming originates in standing wave fields and moves material turbulently away from boundary layers. The third type of acoustic flow takes place in the bulk melt material. The acceleration of material originates from absorption of the ultrasound wave momentum. Typically this kind of flow is slow, compared to the first two types, with speeds in the range 0.1 to $5 \mathrm{~m} / \mathrm{s}$. The speed increases when cavitation starts. Although it is easy to detect in transparent liquids, determination of speed and observation of interaction with cavitation in a metallic melt is more difficult. The theory of acoustic streaming is described in more detail in [11].

Both acoustic streaming and cavitation contribute positively to the refinement of a metal's microstructure, because dispersion and transfer of nuclei for the solidification process are increased. Figure 3 illustrates the occurrence of cavitation and acoustic streaming in a metallic melt. Ishiwata et al. [12] investigated and modelled acoustic streaming in an aluminium melt and water and found the speed of acoustic streaming is significantly dependent on the amplitude of ultrasonic vibration. In a cylindrical mould, the highest speed of acoustic streaming was found directly under the sonotrode, whereas the speed was significantly less in areas further down and beside the tip.

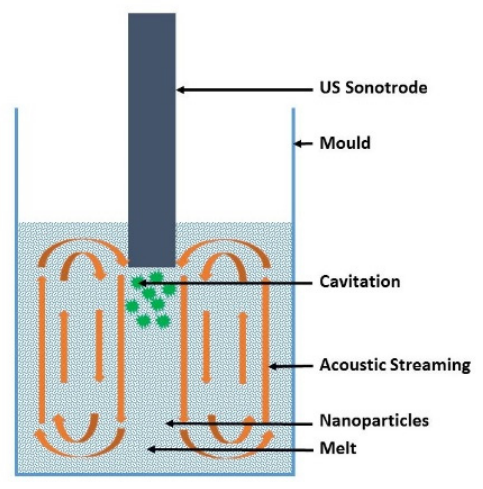

Figure 3. Sketch of cavitation and acoustic streaming in a metallic melt treated with US. 


\subsection{Effect of Ultrasound on Magnesium Alloys}

Degassing: In [13] Eskin describes experiments with an Mg-Al-Zn alloy using UST for degassing. It showed that the hydrogen content could be reduced significantly, to half the content in the untreated alloy. Degassing was the first commercial application of ultrasonic technology for light metals, especially aluminium. It is based on the absorption of hydrogen by cavitation bubbles during their growing phase. Tests with aluminium alloys have shown that the degassing of aluminium alloys increases with increasing intensity of ultrasound [14].

Grain refinement and particle refinement: Pure magnesium, AM60 and AZ91 were cast with and without ultrasonic treatment and their grain sizes and strengths were determined [15]. It turned out that all three materials had significantly smaller grains after $10 \mathrm{~min}$ of ultrasound. For pure magnesium, the grain size reduced from $500 \mu \mathrm{m}$ to $175 \mu \mathrm{m}$, for AZ91 from $205 \mu \mathrm{m}$ to $125 \mu \mathrm{m}$ and for AM60 from $200 \mu \mathrm{m}$ to $90 \mu \mathrm{m}$. The number of trapped inclusions (oxides) was significantly higher after treatment, but the size of the particles was reduced. This grain refining effect increases with increasing frequency, intensity and treatment duration. AZ91D melt was treated with US in the semi-solid state at $580{ }^{\circ} \mathrm{C}$, in order to evaluate its influence on microstructure and mechanical properties in [16]. Ultrasonic power of $0.4,0.6$ and $0.8 \mathrm{~kW}$, which corresponds to intensities of 3.2, 7.65 , and $19.6 \mathrm{~W} / \mathrm{cm}^{2}$, were applied to the slurry. The finest grain size and best globularity could be observed in the $0.6 \mathrm{~kW}$ trials, which is assumed to be the balance point between a lower energy that is not able to refine grains and a higher energy that raises the melt temperature overmuch. Aghayani et al. investigated not only the microstructural changes, but also the phase amount and distribution, and strength in a conventional sand cast AZ91 alloy [17]. It was found that with UST $(20 \mathrm{kHz} ; 120 \mathrm{~W}$, $240 \mathrm{~W}, 360 \mathrm{~W})$ applied for five minutes it significantly influences the size and sphericity of $\alpha-\mathrm{Mg}$ dendrites as well as the intermetallic particles $\mathrm{Mg}_{2} \mathrm{Si}, \mathrm{MnFeAl}(\mathrm{Si})$, and $\mathrm{Mg}_{17} \mathrm{Al}_{12}$. The effects of an increase in US power were smaller grains or intermetallic particles, which are more spherical and better distributed in size. These microstructural changes were imputed to streaming and cavitation during UST. An increase in the tensile strength was attributed to refinement of $\mathrm{Mg}_{17} \mathrm{Al}_{12}$ and its less continuous distribution. Bhingole et al. processed AZ91 with UST, as well [18,19]. Ultrasonic intensities of $1.34 \mathrm{~kW} / \mathrm{cm}^{2}, 2.69 \mathrm{~kW} / \mathrm{cm}^{2}$, and $4.031 \mathrm{~kW} / \mathrm{cm}^{2}$ corresponding to amplitudes of $15 \mu \mathrm{m}$, $30 \mu \mathrm{m}$, and $45 \mu \mathrm{m}$ respectively, were each applied for one minute. With increasing intensity the grain size decreased from $120 \mu \mathrm{m}$ to $20 \mu \mathrm{m}$ and Vickers hardness increased simultaneously. The $\beta$-phase $\mathrm{Mg}_{17} \mathrm{Al}_{12}$ appeared well distributed at the grain boundaries in the US-treated alloys.

\section{Nanocomposites Processing}

\subsection{In Situ Processing}

In situ composite processing based on AZ91 with the addition of magnesium nitrate $\mathrm{Mg}\left(\mathrm{NO}_{3}\right)_{2}$ under UST is described in [20]. $\mathrm{MgO}$ and $\mathrm{Al}_{2} \mathrm{O}_{3}$ forms during US treatment of the mixture and compared to untreated materials better de-agglomeration, distribution and wetting can be observed. A refined microstructure is the outcome after solidification. Compared to untreated AZ91, hardness, yield strength, and the strain hardening exponent increase by $64 \%, 43 \%$, and $115 \%$ respectively, when $6.5 \%$ of the oxides have formed. The wear resistance also improves with an increasing amount of oxides formed in situ.

The same group of scientists published an investigation into US-assisted, in situ-processed AZ91 with the addition of silicon [21]. Silicon particles with a diameter of $4 \mathrm{~mm}$ were added to the melt in 3 and $5 \mathrm{wt} \%$. During dissolution of silicon the following chemical reaction took place spontaneously:

$$
2 \mathrm{Mg}+\mathrm{Si} \rightarrow \mathrm{Mg}_{2} \mathrm{Si}
$$

The addition of silicon increased the hardness compared to unreinforced AZ91 significantly, at the same time the grain size was reduced (see Table 1). The ultimate compressive strength increased by 
90\% compared to AZ91 without the addition of Si and ductility was also improved. Both these are assumed to be due to grain size reduction that is activated by heterogeneous nucleation improvement from the $\mathrm{Mg}_{2} \mathrm{Si}$ particles. Wear resistance was improved as well.

Table 1. Hardness and grain size of AZ91 and in situ $\mathrm{Mg}_{2} \mathrm{Si}$ reinforced AZ91, data from [21].

\begin{tabular}{cccc}
\hline Property & AZ91 & AZ91 + 3Si & AZ91 + 5Si \\
\hline Grain size $[\mu \mathrm{m}]$ & 73 & 51 & 40 \\
Hardness $[\mathrm{VHN}]$ & $65.2 \pm 3$ & $97.4 \pm 3$ & $108.2 \pm 4$ \\
\hline
\end{tabular}

\subsection{AlN Reinforcement}

Cao et al. published research on an AZ91 magnesium alloy reinforced by nano-AlN and processed using US (17.5 kHz and $3.5 \mathrm{~kW})$ [22]. Tensile strength was significantly improved at room temperature and $200{ }^{\circ} \mathrm{C}$, respectively, while ductility was retained.

Commercial magnesium alloy Elektron21 (Mg-2.8Nd-1.2Gd-0.4Zr-0.3Zn) was reinforced with $1 \mathrm{wt} \%$ AlN nanoparticles using power ultrasound of $0.3 \mathrm{~kW}$ and $20 \mathrm{kHz}$ frequency for $5 \mathrm{~min}$ [23]. In order to determine the effect of nanoparticle addition alone, the pure Elektron21 was treated in the same way and both materials were compared in terms of microstructure and mechanical properties at room and elevated temperatures. Figure 4 shows the microstructure of both materials. Unreinforced Elektron21 has a globular microstructure with a grain size of $80.1 \mu \mathrm{m}$, whereas the structure of Elektron21 with $1 \mathrm{wt} \%$ AlN nanoparticles appears more dendritic and has smaller grains; with a grain size of $74.1 \mu \mathrm{m}$. Hardness is not affected by nanoparticles in Elektron21. The mechanical properties at RT and $240{ }^{\circ} \mathrm{C}$ are shown in Table 2. No significant differences can be observed.

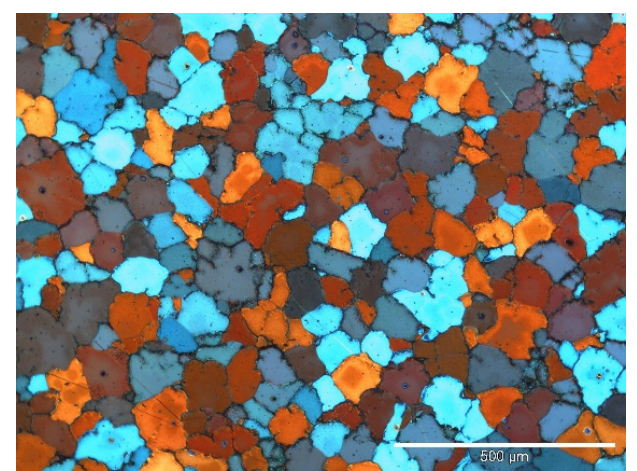

(a)

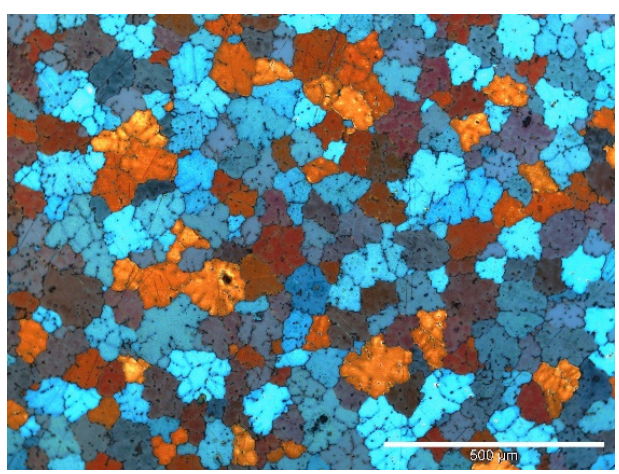

(b)

Figure 4. Optical microscopy pictures. (a) Elektron21; and (b) Elektron 21 with 1 wt \% AlN nanoparticles, reproduced with permission from [23], Elsevier, 2016.

Table 2. Mechanical properties at RT and $240{ }^{\circ} \mathrm{C}$. CYS: compressive yield strength, UCS: ultimate compressive strength, TYS: tensile yield strength, UTS: ultimate tensile strength, E: elongation at fracture, data from [23].

\begin{tabular}{cccc}
\hline Property & Temperature $\left[{ }^{\circ} \mathbf{C}\right]$ & Elektron21 & Elektron21 + 1 wt \% AlN \\
\hline CYS [MPa] & RT & $92.4 \pm 0.8$ & $88.0 \pm 1.0$ \\
UCS [MPa] & RT & $316.8 \pm 1.5$ & $315.7 \pm 0.8$ \\
E [\%] & RT & $21.6 \pm 0.8$ & $22.1 \pm 0.6$ \\
TYS [MPa] & RT & $115 \pm 5$ & $107 \pm 3$ \\
UTS [MPa] & RT & $229 \pm 10$ & $226 \pm 3$ \\
E [\%] & RT & $12 \pm 3$ & $14 \pm 1$ \\
TYS [MPa] & $240^{\circ} \mathrm{C}$ & $86 \pm 7$ & $80 \pm 2$ \\
UTS [MPa] & $240^{\circ} \mathrm{C}$ & $214 \pm 15$ & $217 \pm 8$ \\
E [\%] & $240^{\circ} \mathrm{C}$ & $28 \pm 1$ & $27 \pm 1$ \\
\hline
\end{tabular}


Compression creep tests at $240{ }^{\circ} \mathrm{C}$ were performed on both materials. Constant stresses were applied to cylinders of $6 \mathrm{~mm}$ diameter and $15 \mathrm{~mm}$ length and their deformation was recorded over time. Figure 5a shows the creep curves of both materials tested at $240{ }^{\circ} \mathrm{C}$ and $140 \mathrm{MPa}$. Figure $5 \mathrm{~b}$ shows the creep rates of both tests over time. Obviously the minimum creep rate of nanoparticle reinforced Elektron21 is significantly lower compared to unreinforced Elektron21. This was true for all tests at different stresses at $240{ }^{\circ} \mathrm{C}$, as can be seen in Figure 6. TEM investigations have shown that AlN nanoparticles appear in the eutectic region and in $\mathrm{Mg}$ grains close to it. This appears to strengthen the eutectic and grain boundaries and this may be the reason for improved creep strength.

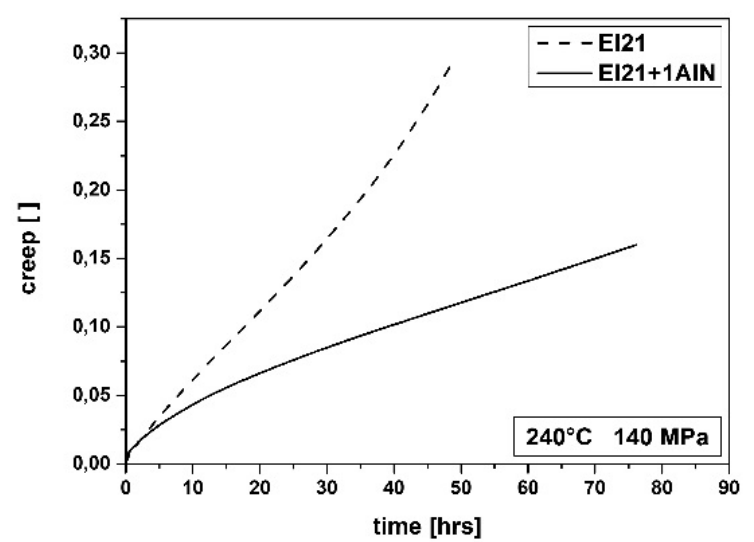

(a)

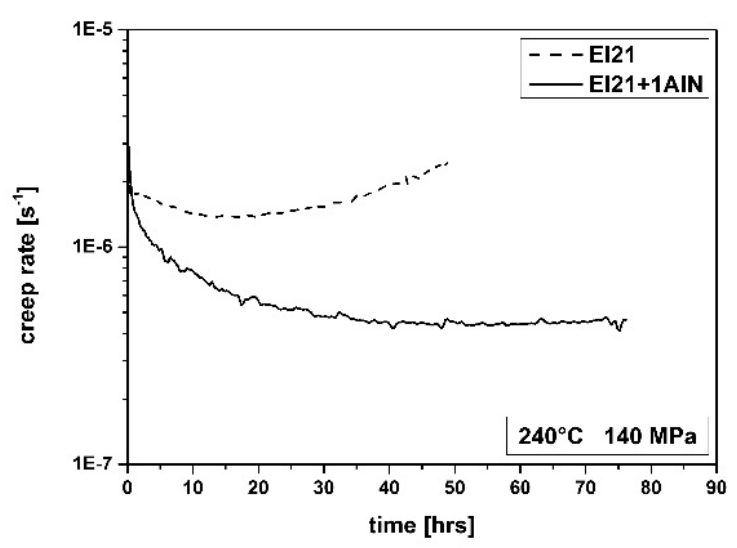

(b)

Figure 5. (a) Creep curves of Elektron 21 and Elektron $21+1 \mathrm{wt} \% \mathrm{AlN}$; (b) creep rate over time from tests at $240{ }^{\circ} \mathrm{C}$ and $140 \mathrm{MPa}$ constant stress, reproduced with permission from [23], Elsevier, 2016.

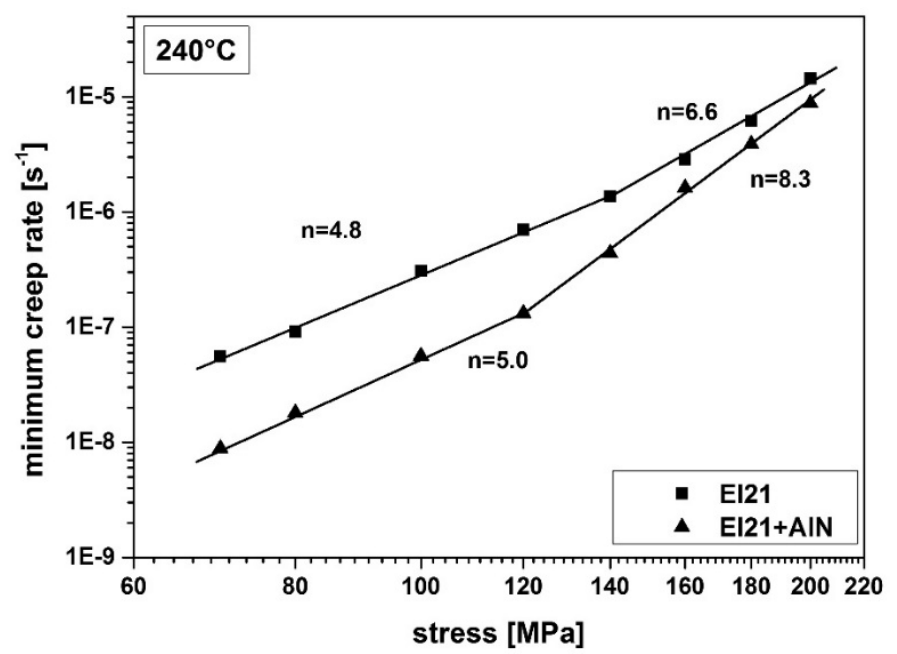

Figure 6. Double logarithmic plot of minimum creep rate versus applied stress from tests performed at $240{ }^{\circ} \mathrm{C}$, reproduced with permission from [23], Elsevier, 2016.

The same manufacturing process was used to reinforce the die casting alloy AM60 with $1 \mathrm{wt} \%$ AlN nanoparticles [24]. AM60 is an alloy that is used intensively in the automotive industry and has excellent room temperature properties and good ductility. In vehicles, components made of AM60 include steering wheels, housings, seat shells, etc., which are not exposed to higher temperatures. These parts are produced by die casting and used in as-cast condition. During their solidification, a fine-grained structure is formed by the die casting, which unfortunately contains $2-4 \%$ porosity due to the turbulent flow of the melt while filling the mould. This porosity makes heat treatment and welding of die cast parts impossible. 
After the AM60 has been ultrasonically reinforced with AIN nanoparticles, a microstructure is formed that is comparable to that of die cast AM60. An immense grain refinement from $1277.0 \pm 301.3 \mu \mathrm{m}$ to only $84.9 \pm 6.2 \mu \mathrm{m}$ occurred, see Figure 7. A significant increase of $103 \%$ in YS (91.2 MPa compared to 44.9 MPa) and 115\% in UTS (235.1 MPa compared to 109.3 MPa) could be observed in room temperature tensile tests. As mentioned, reinforcement with microparticles or fibres usually lowers the ductility significantly, but in this case the AIN nanoparticle addition more than doubles the elongation to failure: an increase of $140 \%$ was observed by addition of AlN nanoparticles (15.4\% compared to $6.4 \%)$ [24].

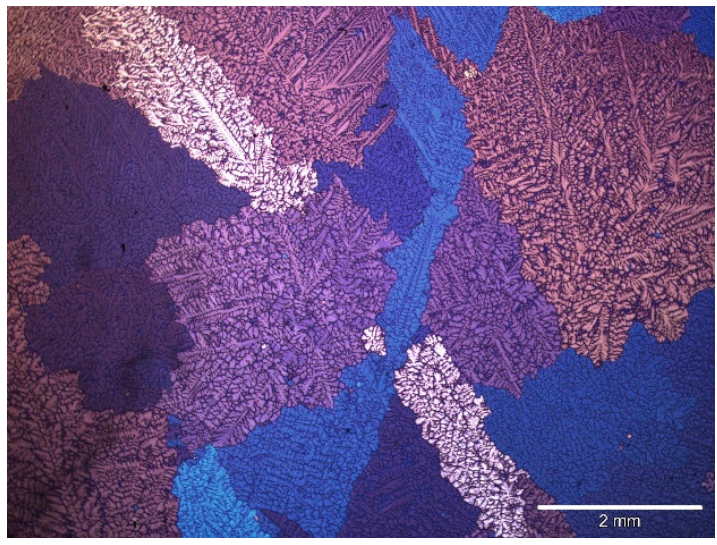

(a)

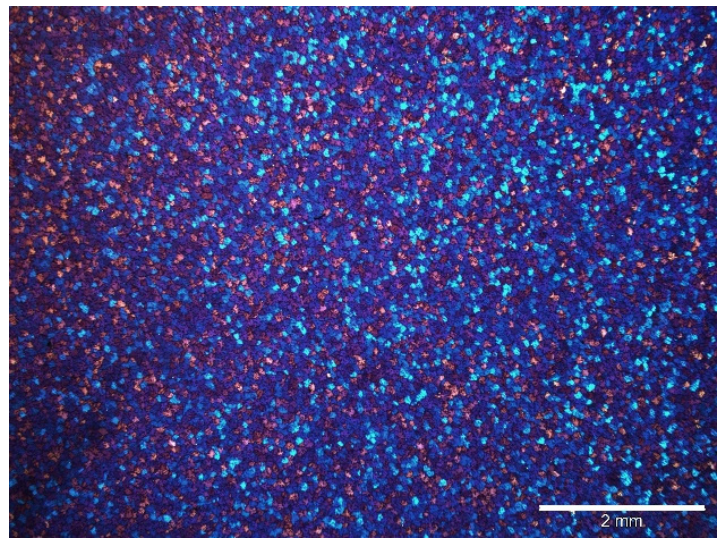

(b)

Figure 7. Microstructure of (a) AM60; and (b) AM60 + AlN [24].

Calculation of the contributions to strengthening show that the largest portion is attributable to grain refinement. This contribution is $42.7 \mathrm{MPa}$. The additional contribution of Orowan strengthening by the introduction of nanoparticles, which inhibit dislocation movement, is only about $8.3 \mathrm{MPa}$, and contributions from other strengthening mechanisms are negligible [24]. Table 3 gives the properties of AM60 and the AM60-based nanocomposite.

Table 3. Grain size, hardness, density, porosity proportion, and mechanical properties of the materials investigated, data from [24].

\begin{tabular}{ccc}
\hline Property & AM60 & AM60 + AlN \\
\hline Grain size [ $\mu \mathrm{m}]$ & $1277.0 \pm 301.3$ & $84.9 \pm 6.2$ \\
Hardness [HV5] & $48.0 \pm 4.0$ & $46.4 \pm 6.0$ \\
Density [g/cm 3 ] & $1.7848 \pm 0.0004$ & $1.783 \pm 0$ \\
Porosity [\%] & - & 0.919 \\
Yield strength ][[MPa] & $44.9 \pm 6.9$ & $91.2 \pm 3.8$ \\
UTS [MPa] & $109.3 \pm 19.2$ & $235.1 \pm 6.4$ \\
Elongation [\%] & $6.4 \pm 3.4$ & $15.4 \pm 4.2$ \\
\hline
\end{tabular}

\section{3. $\mathrm{Al}_{2} \mathrm{O}_{3}$ Reinforcement}

Magnesium alloys AZ91 and Elektron21 (El21) were reinforced with $\mathrm{Al}_{2} \mathrm{O}_{3}$ and $\mathrm{Al}_{2} \mathrm{O}_{3}-\mathrm{AlOOH}$ using an ultrasound-assisted melt-stirring process, followed by permanent mould chill casting [25]. The composition of both commercial alloys is given in Table 4. After incorporation of alumina-based particles in magnesium alloy melt, a rapid chemical reaction with the formation of $\mathrm{MgO}$ occurred. Aluminium occurred in the eutectic region of the Elektron21 alloy thereafter. The occurrence of submicron $\mathrm{MgO}$ particles is expected to improve the wettability of the matrix and to help avoid particle agglomeration. 
Table 4. Composition of AZ91 and Elektron21 in wt \%, data from [25].

\begin{tabular}{cccccccc}
\hline Alloy & Al & Zn & Mn & Nd & Gd & Zr & Mg \\
\hline AZ91 & 8.71 & 0.66 & 0.22 & - & - & - & Bal. \\
El21 & - & $0.2-0.5$ & - & $2.6-3.1$ & $1.0-1.7$ & Satur. & Bal. \\
\hline
\end{tabular}

The creep behaviour of magnesium alloy AS41 reinforced with 2 and 5 wt $\% \mathrm{Al}_{2} \mathrm{O}_{3}$ nanoparticles using ultrasound-assisted stirring was investigated in [26]. Alumina nanoparticles of $50 \mathrm{~nm}$ diameter were added to the AS41 melt, and stirred for 15-20 min. Sonication for three minutes at $20 \mathrm{kHz}$ with an amplitude of $60 \mu \mathrm{m}$ followed the stirring. Indentation creep tests were performed at temperatures of $175,200,225$, and $250{ }^{\circ} \mathrm{C}$ and stresses of $109.2,124.8$, and $140.0 \mathrm{MPa}$, respectively. It was found that the creep resistance increases with increasing alumina content. This effect is attributed to Orowan strengthening by the nanoparticles and a good distribution of finer $\mathrm{Mg}_{2} \mathrm{Si}$ precipitates due to sonication. After calculation of stress exponents and activation energies, according to the equations describing the stress and temperature dependence of minimum creep rates, pipe diffusion-controlled dislocation creep is assumed to be the rate controlling deformation mechanism during indentation creep.

\subsection{SiC Reinforcement}

AZ91 magnesium alloy was reinforced using ultrasonic treatment with $\beta$-SiC nanoparticles of $40 \mathrm{~nm}$ [27]. Nanocomposites containing $0.5,1.0,1.5$, and $2.0 \mathrm{wt} \% \mathrm{SiC}$ were compared with unreinforced AZ91. Optical microscopy shows a grain refining effect of the nanoparticles. The mechanical properties are plotted in Figure 8. It can be seen that a $1.0 \mathrm{wt} \%$ nano-SiC addition best improved the strength and ductility compared to unreinforced AZ91.

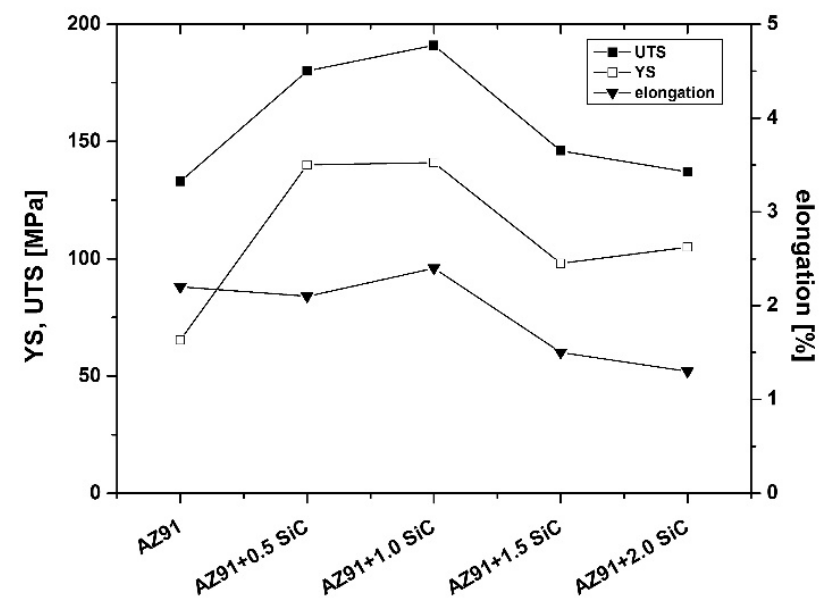

Figure 8. Tensile properties of nano-SiC/AZ91 at room temperature, data from [27].

A total of $1.5 \mathrm{wt} \%$ of $\mathrm{SiC}$ nanoparticles ( $50 \mathrm{~nm}$ size) were added to a $\mathrm{Mg}-6 \mathrm{Zn}$ alloy using UST with $17.5 \mathrm{kHz}$ frequency and $3.5 \mathrm{~kW}$ power [28]. Tensile tests showed that both yield and ultimate tensile strength can be increased by additions of $40 \%$ and $34 \%$, respectively, of nano-SiC, yet the ductility is retained. TEM investigations showed that a good bonding between $\mathrm{SiC}$ particles and $\mathrm{Mg}-6 \mathrm{Zn}$ matrix could be achieved. This research group also published results of their mechanical and microstructural investigations into nano-SiC reinforced AS21 and AS41 produced with ultrasound-assisted casting [29]. In both cases $2 \mathrm{wt} \%$ were added and the nano-composites were compared to their unreinforced alloys. A grain refining effect could be observed and tensile strength in both cases was significantly improved.

$\mathrm{SiC}$ particles with a diameter of $50 \mathrm{~nm}$ were stirred into a pure magnesium melt with the use of ultrasound assistance [30]. This was done at a temperature of $700{ }^{\circ} \mathrm{C}$. After stirring, the melt was poured into a steel mould preheated to $350^{\circ} \mathrm{C}$, which formed the tensile specimens. The pure 
magnesium was reinforced with $0.5,1,2$, and $4 \mathrm{wt} \%$ nano-SiC and the mechanical properties are shown in Table 5. The best strength and at the same time the best ductility can be seen with the $2 \%$ nano-SiC reinforcement. At $4 \% \mathrm{SiC}$ the ductility decreased strongly, which may also be due to a different melt treatment. The melt was not filtered before casting.

Table 5. Average mechanical properties of $\mathrm{Mg}$ and $\mathrm{Mg} / \mathrm{SiC}$ nanocomposites, data from [30].

\begin{tabular}{cccc}
\hline Material & YS [MPa] & UTS [MPa] & E [\%] \\
\hline Mg & 20 & 89.6 & 14.0 \\
Mg-0.5SiC & 28.3 & 120.7 & 15.5 \\
Mg-1SiC & 30.3 & 124.1 & 14.2 \\
Mg-2SiC & 35.9 & 131.0 & 12.6 \\
Mg-4SiC & 47.6 & 106.9 & 5.5 \\
\hline
\end{tabular}

AZ91 magnesium alloy (Mg-9.07Al-0.68Zn-0.21Mn) was reinforced with $1 \mu \mathrm{m}$ SiC particles using semi-solid stirring assisted by ultrasonic vibration [31]. The properties of the materials with additions of 3 and 5 vol \% particles were compared with unreinforced AZ91 cast without stirring and ultrasonic vibration. The grain sizes in the $3 \mathrm{vol} \%$ composite are significantly refined compared to AZ91 without addition of $\mathrm{SiC}$. The $\beta$-phase $\mathrm{Mg}_{17} \mathrm{Al}_{12}$ changed its morphology to fine lamellae in the 3 vol \% composite. In both composites, the particles are distributed along the grain boundaries, only a few are dispersed in the matrix. It is probable that particle pushing occurred during solidification. For the 3 vol \% composite the yield strength and ultimate tensile strength are improved, while ductility remained the same. For the $5 \mathrm{vol} \%$ composite, the YS also increased, but UTS and elongation decreased, due to agglomerates of $\mathrm{SiC}$ appearing in the microstructure.

Again, the magnesium alloy AZ91 was reinforced with $\beta$-SiC of $40 \mathrm{~nm}$ diameter with mass fractions of $0.5,1.0,1.5$, and $2.0 \mathrm{wt} \%$ [32]. Particles were introduced to the melt at a temperature of $650{ }^{\circ} \mathrm{C}$ under ultrasound of $4 \mathrm{~kW}$ power and $20 \mathrm{kHz}$ frequency for $10 \mathrm{~min}$ of ultrasonic treatment. Figure 9a shows the grain size and hardness of AZ91 and these nanocomposites. It can be seen that with increasing $\mathrm{SiC}$ content the grain size decreases and hardness increases. Strength shown in Figure $9 \mathrm{~b}$ reaches a maximum at $1 \mathrm{wt} \% \mathrm{SiC}$ content and decreases again with more addition. Compared to unreinforced AZ91 the composite with $1 \mathrm{wt} \%$ nano-SiC has more than double the yield strength.

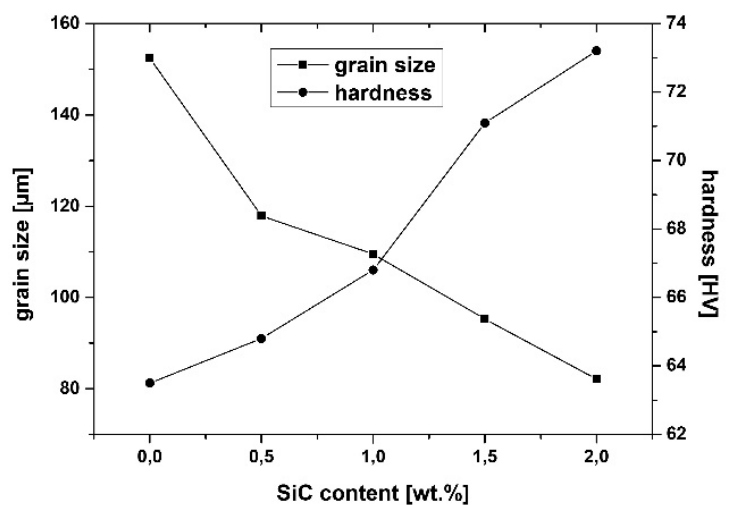

(a)

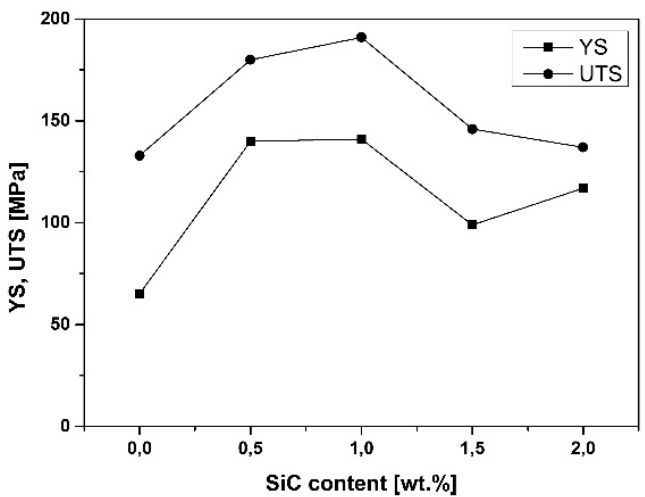

(b)

Figure 9. (a) Grain size, hardness; and (b) mechanical properties of AZ91 and its SiC reinforced nanocomposites, data from [32].

The magnesium alloy AZ91 was again reinforced with SiC nanoparticles of $50 \mathrm{~nm}$ size [33]. Ultrasonic treatment was applied for $30 \mathrm{~min}$ at $0.6 \mathrm{~kW}$ with $20 \mathrm{kHz}$ frequency. The grain size of materials was reduced from $90 \mu \mathrm{m}$ in the AZ91 to $60 \mu \mathrm{m}$ in the $0.5 \mathrm{wt} \%$ SiC-reinforced AZ91. This significant grain refinement is attributed to a heterogeneous nucleation effect of SiC nanoparticles. 
The reason for this is that there is only a small mismatch of $3.96 \%$ between the (111) crystal face of $\mathrm{SiC}$ and the (0001) crystal face of the Mg lattice. The mechanical properties are given in Table 6. It is obvious that not only strength is significantly improved, but also ductility by $83 \%$.

Table 6. Mechanical properties of AZ91 and its $0.5 \mathrm{SiC}$ nanocomposite, data from [33].

\begin{tabular}{cccc}
\hline Material & YS [MPa] & UTS [MPa] & E [\%] \\
\hline AZ91 & 104 & 174 & 3.6 \\
AZ91 + 0.5SiC & 124 & 216 & 6.6 \\
\hline
\end{tabular}

Magnesium-zinc alloys with different zinc content (4, 6, and $8 \mathrm{wt} \%$ ) were reinforced with $1.5 \mathrm{wt} \%$ $\beta-\mathrm{SiC}$ of $50 \mathrm{~nm}$ average diameter for $\mathrm{Mg}-4 \mathrm{Zn}$ and $\mathrm{Mg}-6 \mathrm{Zn}$, and with $3.0 \mathrm{wt} \%$ for $\mathrm{Mg}-8 \mathrm{Zn}$. The SiC nanoparticles were introduced to the melt at $700{ }^{\circ} \mathrm{C}$ with US assistance [34]. A niobium sonotrode generating a frequency of $17.5 \mathrm{kHz}$ and $4.0 \mathrm{~kW}$ power was used for sonication. The materials were tensile tested at room temperature. Significant improvements in yield strength, UTS and ductility were found, as can be seen in Table 7.

Table 7. Mechanical properties of Mg-Zn alloys and its SiC reinforced nanocomposites, data from [34].

\begin{tabular}{cccc}
\hline Material & YS [MPa] & UTS [MPa] & E [\%] \\
\hline Mg-4Zn & $44 \pm 2$ & $112 \pm 14$ & $5 \pm 1$ \\
Mg-4Zn + 1.5 SiC & $67 \pm 4$ & $199 \pm 6$ & $10 \pm 1$ \\
Mg-6Zn & $51 \pm 4$ & $136 \pm 19$ & $5 \pm 1$ \\
Mg-6Zn + 1.5 SiC & $79 \pm 5$ & $194 \pm 15$ & $7 \pm 1$ \\
Mg-8Zn * & 81 & 152 & 3 \\
* Indicates data taken from only two samples. The other data from not less than four samples.
\end{tabular}

A magnesium alloy containing 18\% zinc was reinforced with 6 vol \% SiC nanoparticles (average diameter 40-50 nm) using a combination of semi-solid stirring and ultrasonic dispersion in the liquid phase [35]. Optical investigations showed a very homogeneous distribution of the particles in the matrix. Hardness measurements showed that the hardness of the nanocomposite with $183 \mathrm{~kg} / \mathrm{mm}^{2}$ is about $140 \%$ higher than that of the alloy with $76 \mathrm{~kg} / \mathrm{mm}^{2}$.

Song et al. tried to simulate the influence of ultrasonic power, ultrasonic frequency, ultrasonic processing duration and depth of sonotrode dipped into the melt on the effectiveness of SiC nanoparticle distribution in an AZ91 melt [36]. An optimum set of parameters for nanoparticle distribution is $2 \mathrm{~kW}$ ultrasonic power and $20 \mathrm{kHz}$ frequency with the sonotrode dipped 20-30 mm into the melt and the duration of sonication $120 \mathrm{~s}$. Experimental results confirm this set of parameters for an $\mathrm{SiC}$ addition of $1 \mathrm{vol} \%$ of particles with 30-300 $\mathrm{nm}$ diameter. The nanocomposites show improved mechanical properties induced by grain refinement and Orowan strengthening.

\section{5. $\mathrm{TiB}_{2}$ Reinforcement}

The magnesium alloy AZ91D was reinforced with $\mathrm{TiB}_{2}$ nanoparticles with a diameter of $25 \mathrm{~nm}$ [37]. For stirring in at $700{ }^{\circ} \mathrm{C}$, a niobium sonotrode and an ultrasonic generator were used, which generates an amplitude of $60 \mu \mathrm{m}$ at $20 \mathrm{kHz}$. The process took $15 \mathrm{~min}$.

Mechanical tests at room temperature show an improvement in strength in combination with improved ductility, which can be attributed to a significant reduction in grain size. With a content of $1 \%$ and $2.7 \% \mathrm{TiB}_{2}$, the grain size is reduced by about half. The mechanical properties are summarised in Table 8. 
Table 8. Mechanical properties of AZ91D alloy and its $\mathrm{TiB}_{2}$ nanocomposites, data from [37].

\begin{tabular}{|c|c|c|c|}
\hline Material & YS [MPa] & UTS [MPa] & $\mathrm{E}[\%]$ \\
\hline AZ91 & $88 \pm 3$ & $162 \pm 5$ & $2.88 \pm 0.12$ \\
\hline $\mathrm{AZ} 91+1 \mathrm{TiB}_{2}$ & $104 \pm 1$ & $180 \pm 0$ & $3.33 \pm 0.05$ \\
\hline $\mathrm{AZ} 91+2.7 \mathrm{TiB}_{2}$ & $107 \pm 1$ & $188 \pm 7$ & $4.27 \pm 0.61$ \\
\hline
\end{tabular}

\subsection{Graphene, Carbon Black, and CNT Reinforcement}

Conventional magnesium alloys AZ31, AZ61, and AZ91 were inoculated with 1 wt \% carbon black of $42 \mathrm{~nm}$ average size by $20 \mathrm{kHz}$ ultrasound-assisted stirring, in order to refine the grain size [38]. According to the following equation, the ultrasonic intensity was calculated to be $4.3 \mathrm{~kW} / \mathrm{cm}^{2}$ [9], where $\rho$ is the liquid density $\left(1.584 \mathrm{~g} / \mathrm{cm}^{3}\right.$ for liquid magnesium), $c$ is the speed of sound in molten magnesium $(1500 \mathrm{~m} / \mathrm{s}), f$ is the ultrasonic frequency $(20 \mathrm{kHz})$, and $A$ is the amplitude of the ultrasound (here, $48 \mu \mathrm{m}$ ).

$$
I=\frac{\rho c}{2}(2 \pi f A)^{2}
$$

The effect of carbon black as a grain refiner when ultrasonically stirred into AZ-melts is shown in Figure 10a [38]. Under similar conditions, the AZ91 obviously has the smallest grains and with decreasing aluminium content the grains become larger. This tendency remains when carbon black is introduced, but all alloys show grain size reduction. An additional reduction is reached when after inoculation the melts are ultrasonically treated. Yield strength, ultimate tensile strength and elongation to fracture are all best when carbon black inoculation is accompanied by intensive ultrasound treatment, see Figure 10b-d. It is assumed that the finer grains are responsible for the improvement of mechanical properties.

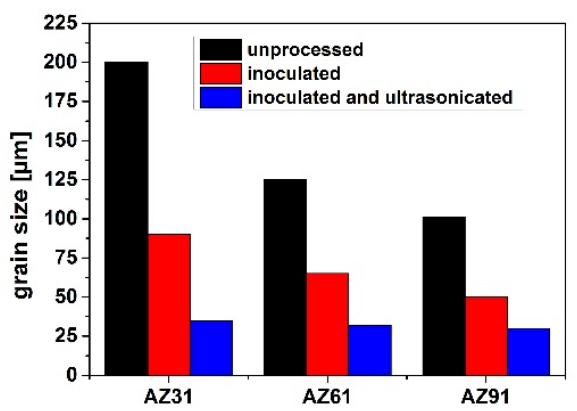

(a)

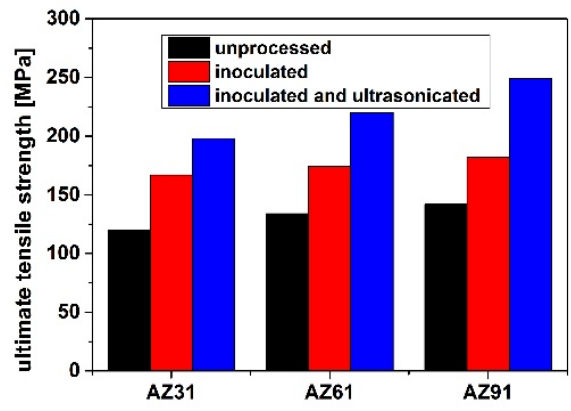

(c)

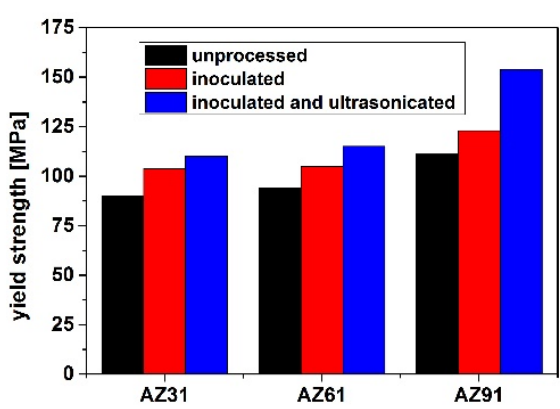

(b)

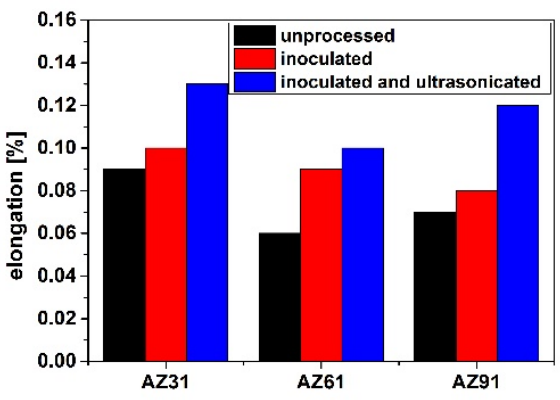

(d)

Figure 10. (a) Grain size; (b) yield strength; (c) ultimate tensile strength; and (d) elongation to fracture of the investigated materials, data from [38].

Chen et al. describe a two-step process for dispersion of graphene nanoplatelets in a pure magnesium matrix [39]. In the first step, graphene is fed into a magnesium melt at $700{ }^{\circ} \mathrm{C}$ and 
ultrasonically treated with an amplitude of $60 \mu \mathrm{m}$ and stirred with ultrasound for $15 \mathrm{~min}$. The graphene nanoplatelets were well distributed in the castings, but were still agglomerated. In order to further disperse them, a friction stir process was applied. Compared to the unreinforced castings of pure magnesium, the hardness increased by $78 \%$ and the strength increased by $64 \%$.

AZ91 magnesium alloy reinforced with carbon nanotubes (CNTs) was processed using UST in [40]. The AZ91 melt was stirred, the CNTs were added, and US-treated for $15 \mathrm{~min}$ with $20 \mathrm{kHz}$ and a maximum power of $1.4 \mathrm{~kW}$. Afterwards the melt was poured into steel moulds and solidified. The grain size of reinforced AZ91 was reduced by $72 \%$ compared to unreinforced AZ91. The mechanical properties are plotted in Figure 11. Strength, as well as ductility, were improved by the addition of $1.5 \%$ CNTs.

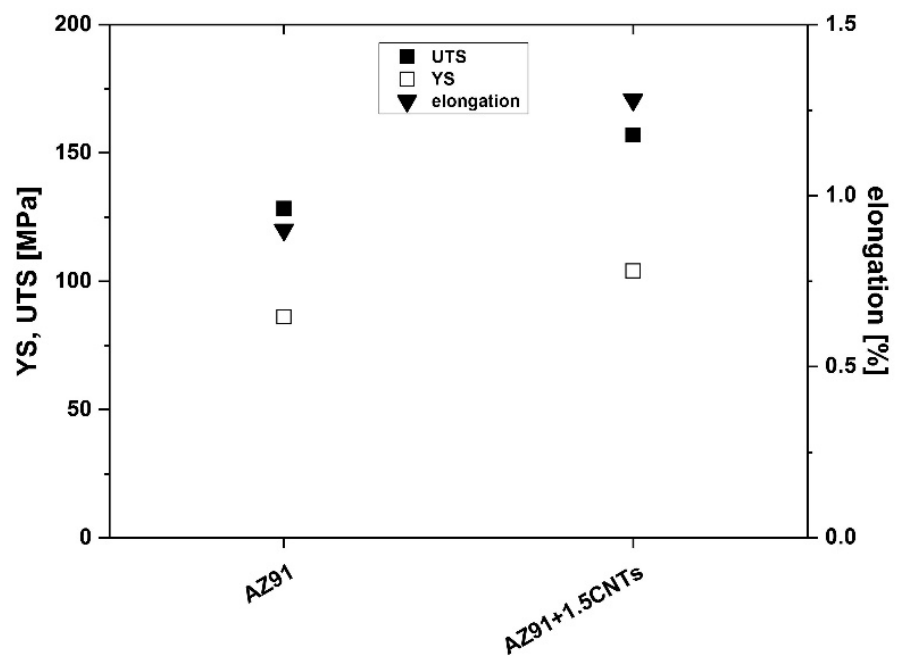

Figure 11. Tensile properties of as cast AZ91 and its composite reinforced with $1.5 \%$ CNTs, data from [40].

In a study by Mussi et al. magnesium alloy AZ91D as the matrix material was reinforced with carbon nano-fibres with a length of $10 \mu \mathrm{m}$ and a diameter $100 \mathrm{~nm}$ [41]. The AZ91D melt was cooled down to a semi-solid state. The slurry was kept at a constant temperature and mechanical stirring started. 1, 2 and $3 \mathrm{vol} \%$ carbon fibres were added to the vortex created by the stirring and the stirring was continued for $20 \mathrm{~min}$ at $590^{\circ} \mathrm{C}$. After stirring, ultrasonic treatment was applied. It was found that an amplitude of $16 \mu \mathrm{m}$ and vibration time of at least $10 \mathrm{~min}$ were needed to disperse the fibres homogeneously.

\section{Conclusions}

Metallurgical melt processes to produce metal matrix nanocomposites that succeed in the dispersion of nanoparticles in the melt with the aid of ultrasonic processes are obviously very effective. This can be seen from significant improvements in the properties of the alloys produced by introducing nanoparticles with UST. Unfortunately, the parameters for ultrasound treatment are sometimes given, but rarely discussed in detail in most publications. These include the frequency and amplitude or energy of ultrasound, the melting temperature and amount of melt, the duration of ultrasound treatment, sonotrode material and immersion depth. A summary of all these process parameters is set out in Table 9. 
Table 9. Ultrasound equipment and processing parameters from all the publications, when given.

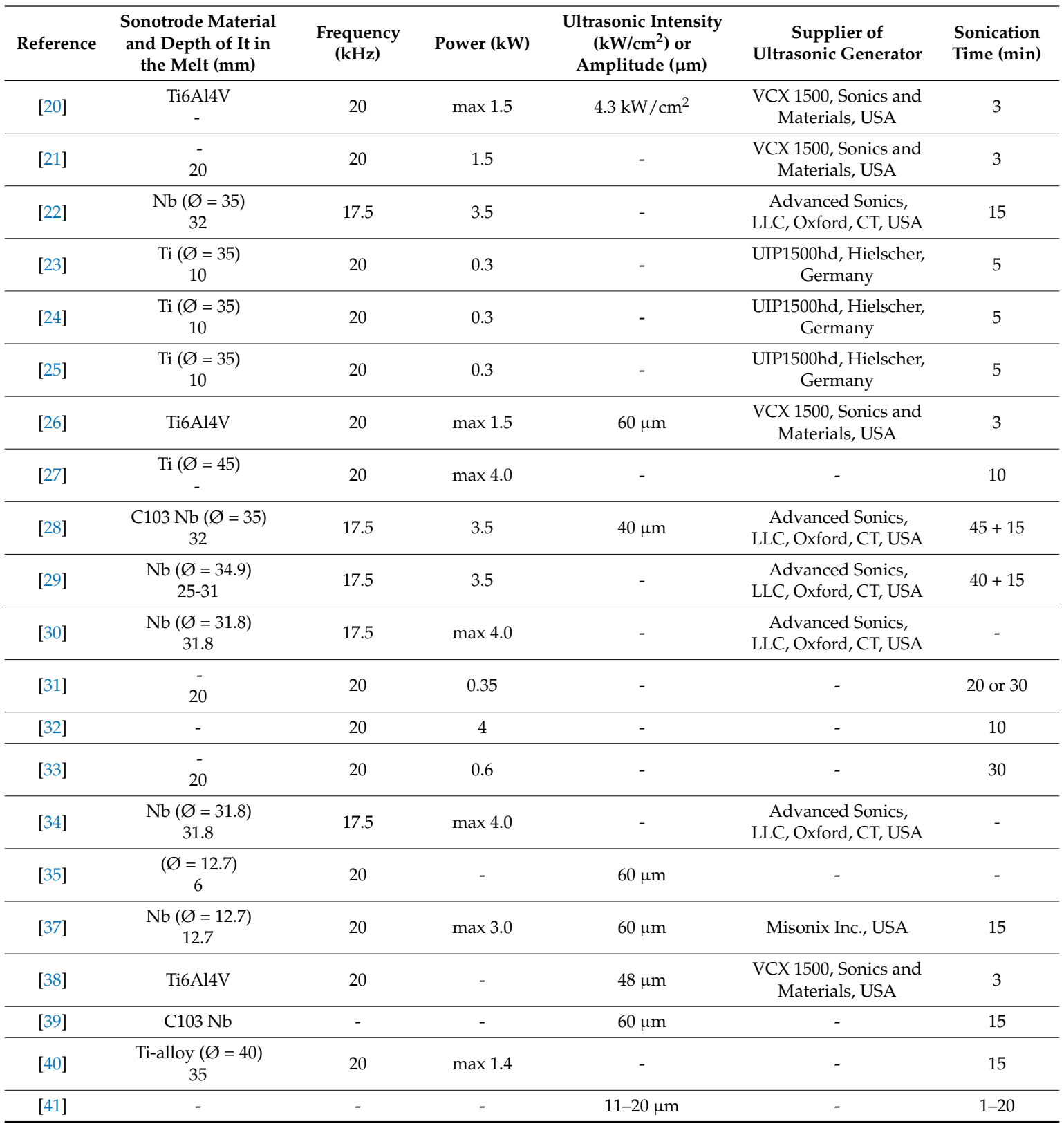

Titanium and Ti6Al4V seem the most promising materials for ultrasonic horns to be made from. This is certainly due to the high melting point $\left(1668{ }^{\circ} \mathrm{C}\right.$ for titanium and $1604{ }^{\circ} \mathrm{C}$ for Ti6Al4V), but also to the high specific strength of both materials. Niobium sonotrodes are also used, with an even higher melting point of $2477^{\circ} \mathrm{C}$. The solubility of titanium in magnesium is very low, but that of niobium in magnesium is not described in the literature. Ultrasonic generators from four manufacturers have been used for dispersing nanoparticles in magnesium melts; these are Hielscher from Germany, Misonix Inc., Sonics and Materials, and Advanced Sonics from the USA. The latter operates with an ultrasonic frequency of $17.5 \mathrm{kHz}$, and all others with $20 \mathrm{kHz}$. The sonication can last between three minutes and one hour. Many of the shorter ultrasonic treatments already show very good results, therefore, it can be assumed that dispersion and deagglomeration occur reasonably quickly. This result is confirmed in [42]. With increased times of stirring, a coarsening of the grains is observed. However, the exact amount of melt processed is never stated in publications, so no general recommendation for the duration of ultrasound treatment is possible. 
The results of individual investigations into nanoparticle-reinforced magnesium or magnesium alloys show a remarkable effect on the mechanical properties of the matrix alloy by the addition of small amounts of nanoparticles using UST. Often a 1 or $2 \%$ addition of $\mathrm{SiC}, \mathrm{Al}_{2} \mathrm{O}_{3}, \mathrm{AlN}$, or carbon-based nanomaterials is sufficient to achieve significant increases in strength. In some cases, it is even shown that more particles tend to lead to a decrease in strength $[27,30,32]$. Noteworthy are doublings in yield strength or tensile strength, as shown in [24] with an addition of only $1 \%$ by weight of AlN nanoparticles. In some cases grain refinement occurs, in other cases the increase in strength is due to dispersion or Orowan strengthening. In the past, strength could only be increased by adding fibres or particles of micrometre size. However, this came always at the expense of ductility. In contrast, with nanoparticles the situation is completely different. An increase in strength is almost always accompanied by an increase in ductility, which is ideal for the use of these nanocomposites as structural materials. In the future, with further research and development in this field, the range of potential applications for these interesting materials will greatly expand.

Conflicts of Interest: The author declares no conflict of interest.

\section{References}

1. Zhu, S.M.; Gibson, M.A.; Easton, M.A.; Nie, J.F. The relationship between microstructure and creep resistance in die-cast magnesium-rare earth alloys. Scr. Mater. 2010, 63, 698-703. [CrossRef]

2. Zhu, S.M.; Easton, M.A.; Gibson, M.A.; Dargusch, M.S.; Nie, J.F. Analysis of the creep behaviour of die-cast Mg-3Al-1Si alloy. Mater. Sci. Eng. 2013, A578, 377-382. [CrossRef]

3. Kubásek, J.; Vojtěch, D.; Martínek, M. Structural characteristics and elevated temperature mechanical properties of AJ62 Mg alloy. Mater. Charact. 2013, 86, 270-282. [CrossRef]

4. Dieringa, H.; Huang, Y.; Wittke, P.; Klein, M.; Walther, F.; Dikovits, M.; Poletti, C. Compression creep response of magnesium alloy DieMag422 containing barium compared with the commercial creep-resistant alloys AE42 and MRI230D. Mater. Sci. Eng. 2013, 585, 430-438. [CrossRef]

5. Huang, Y.; Dieringa, H.; Kainer, K.U.; Hort, N. Understanding effects of microstructural inhomogeneity on creep response-New approaches to improve the creep resistance in magnesium alloys. J. Magnes. Alloys 2014, 2, 124-132. [CrossRef]

6. Eskin, D.G.; Eskin, G.I. Ultrasonic Treatment of Light Alloy Melts, 2nd ed.; CRC Press: Boca Raton, FL, USA, 2014.

7. Suslick, K.S.; Cline, R.E.; Hammerton, D.A. The sonochemical hot spot. J. Am. Chem. Soc. 1986, 108, 5641-5642. [CrossRef]

8. Eskin, G.I. Cavitation mechanism of ultrasonic melt degassing. Ultrason. Sonochem. 1995, 2, S137-S141. [CrossRef]

9. Eskin, G.I. Ultrasonic Treatment of Light Alloy Metallic Melts; Gordon and Breach Science Publishers: Amsterdam, The Netherlands, 1998.

10. Suslick, K.S.; Matula, T.J. Ultrasonic physical mechanisms and chemical effects. In Wiley Encyclopedia of Electrical and Electronics Engineering; Webster, J., Ed.; John Wiley \& Sons, Inc.: Hoboken, NJ, USA, 1999.

11. Zarembo, L.K. Part III: Acoustic streaming. In High-Intensity Ultrasonic Fields; Rozenberg, L.D., Ed.; Springer Science and Business Media: New York, NY, USA, 1971.

12. Ishiwata, Y.; Komarov, S.; Takeda, Y. Investigation of acoustic streaming in aluminum melts exposed to high-intensity ultrasonic irradiation. In Proceedings of the 13th International Conference on Aluminum Alloys (ICAA13), Pittsburgh, PA, USA, 3-7 June 2012.

13. Eskin, G.I. Crystallization of ingots of magnesium alloys with ultrasonic treatment of the melt. Metallurgist 2003, 47, 265-272. [CrossRef]

14. Eskin, G.I. Principles of ultrasonic treatment: Application for light alloys melts. Adv. Perform. Mater. 1997, 4, 223-232. [CrossRef]

15. Chen, Y.-J.; Hsu, W.-N.; Shih, J.-R. The effect of ultrasonic treatment on microstructural and mechanical properties of cast magnesium alloys. Mater. Trans. 2009, 50, 401-408. [CrossRef]

16. Chen, G.; Zhou, T.; Yan, H.; Li, K. Effects of ultrasonic field on microstructure and properties of semi-solid AZ91D magnesium alloy. J. Wuhan Univ. Technol. 2010, 25, 555-560. 
17. Aghayani, M.K.; Niroumand, B. Effects of ultrasonic treatment on microstructure and tensile strength of AZ91 magnesium alloy. J. Alloys Comp. 2011, 509, 114-122. [CrossRef]

18. Bhingole, P.P.; Patel, B.; Chaudhari, G.P. Ultrasonic processing and microstructural analysis of AZ91 magnesium alloy. Mater. Sci. Forum 2012, 702-703, 975-978. [CrossRef]

19. Bhingole, P.; Chaudhari, G. Effect of ultrasonic treatment on the grain refinement and mechanical properties of AZ91 magnesium alloy. Mater. Sci. Forum 2012, 710, 463-468. [CrossRef]

20. Bhingole, P.P.; Chaudhari, G.P.; Nath, S.K. Processing, microstructure and properties of ultrasonically processed in situ $\mathrm{MgO}-\mathrm{Al}_{2} \mathrm{O}_{3}-\mathrm{MgAl}_{2} \mathrm{O}_{4}$ dispersed magnesium alloy composites. Composites 2014, A66, 209-217. [CrossRef]

21. Muley, S.V.; Singh, S.P.; Sinha, P.; Bhingole, P.P.; Chaudhari, G.P. Microstructural evolution in ultrasonically processed in situ AZ91 matrix composites and their mechanical and wear behaviour. Mater. Des. 2014, 53, 475-481. [CrossRef]

22. Cao, G.; Choi, H.; Oportus, J.; Konishi, H.; Li, X. Study on tensile properties and microstructure of cast AZ91D/AlN nanocomposites. Mater. Sci. Eng. 2008, A494, 127-131. [CrossRef]

23. Katsarou, L.; Mounib, M.; Lefebvre, W.; Vorozhtsov, S.; Pavese, M.; Badini, C.; Molina-Aldareguia, J.M.; Cepeda Jimenez, C.; Pérez Prado, M.T.; Dieringa, H. Microstructure, mechanical properties and creep of magnesium alloy Elektron21 reinforced with AlN nanoparticles by ultrasound-assisted stirring. Mater. Sci. Eng. 2016, A659, 84-92. [CrossRef]

24. Dieringa, H.; Katsarou, L.; Buzolin, R.; Szakács, G.; Horstmann, M.; Wolff, M.; Mendis, C.; Vorozhtsov, S.; StJohn, D. Ultrasound assisted casting of an AM60 based metal matrix nanocomposite, its properties, and recyclability. Metals 2017, 7, 388. [CrossRef]

25. Mounib, M.; Pavese, M.; Badini, C.; Lefebvre, W.; Dieringa, H. Reactivity and microstructure of $\mathrm{Al}_{2} \mathrm{O}_{3}$-reinforced magnesium-matrix composites. Adv. Mater. Sci. Eng. 2014. [CrossRef]

26. Kumar, H.; Chaudhari, G.P. Creep behavior of AS41 alloy matrix nano-composites. Mater. Sci. Eng. A 2014, 607, 435-444. [CrossRef]

27. Shiying, L.; Feipeng, G.; Qiongyuan, Z.; Wenzhen, L. Mechanical properties and microstructures of nano-sized $\mathrm{SiC}$ particle reinforced AZ91D nanocomposites fabricated by high intensity ultrasonic assisted casting. Mater. Sci. Forum 2009, 618-619, 449-452.

28. Cao, G.; Choi, H.; Konishi, H.; Kou, S.; Lakes, R.; Li, X. Mg-6Zn/1.5\%SiC nanocomposites fabricated by ultrasonic cavitation-based solidification processing. J. Mater. Sci. 2008, 43, 5521-5526. [CrossRef]

29. Cao, G.; Konishi, H.; Li, X. Mechanical properties and microstructure of SiC-reinforced Mg-(2,4)Al-1Si nanocomposites fabricated by ultrasonic cavitation based solidification processing. Mater. Sci. Eng. 2008, A486, 357-362. [CrossRef]

30. Cao, G.; Konishi, H.; Li, X. Mechanical properties and microstructure of $\mathrm{Mg} / \mathrm{SiC}$ nanocomposites fabricated by ultrasonic cavitation based nanomanufacturing. J. Manuf. Sci. Eng. 2008, 130, 031105. [CrossRef]

31. Nie, K.B.; Wang, X.J.; Wu, K.; Hu, X.S.; Zheng, M.Y.; Xu, L. Microstructure and tensile properties of micro-SiC particles reinforced magnesium matrix composites produced by semisolid stirring assisted ultrasonic vibration. Mater. Sci. Eng. 2011, A528, 8709-8714. [CrossRef]

32. Jia, X.Y.; Liu, S.Y.; Gao, F.P.; Zhang, Q.Y.; Li, W.Z. Magnesium matrix nanocomposites fabricated by ultrasonic assisted casting. Int. J. Cast Metals Res. 2009, 22, 196-199. [CrossRef]

33. Wang, Z.-H.; Wang, X.-D.; Zhao, Y.-X.; Du, W.-B. SiC nanoparticles reinforced magnesium matrix composites fabricated by ultrasonic method. Trans. Nonferrous Metals Soc. China 2010, 20, s1029-s1032. [CrossRef]

34. De Cicco, M.; Konishi, H.; Cao, G.; Choi, H.S.; Turng, L.-S.; Perepezko, J.H.; Kou, S.; Lakes, R.; Li, X. Strong, ductile magnesium-zinc nanocomposites. Metall. Mater. Trans. 2009, A40, 3038-3045. [CrossRef]

35. Chen, L.-Y.; Peng, J.-Y.; Xu, J.-Q.; Choi, H.; Li, X.-C. Achieving uniform distribution and dispersion of a high percentage of nanoparticles in metal matrix nanocomposites by solidification processing. Scr. Mater. 2013, 69, 634-637. [CrossRef]

36. Song, S.; Zhou, X.; Li, L.; Ma, W. Numerical simulation and experimental validation of SiC nanoparticle distribution in magnesium melts during ultrasonic cavitation based processing of magnesium matrix composites. Ultrason. Sonochem. 2015, 24, 43-54. [CrossRef] [PubMed]

37. Choi, H.; Sun, Y.; Slater, B.P.; Konishi, H.; Li, X. AZ91D/TiB2 Nanocomposites Fabricated by Solidification Nanoprocessing. Adv. Eng. Mater. 2012, 14, 291-295. [CrossRef] 
38. Bhingole, P.P.; Chaudhari, G.P. Synergy of nano carbon black inoculation and high intensity ultrasonic processing in cast magnesium alloys. Mater. Sci. Eng. A 2012, 556, 954-961. [CrossRef]

39. Chen, L.-Y.; Konishi, H.; Fehrenbacher, A.; Ma, C.; Xu, J.-Q.; Choi, H.; Xu, H.-F.; Pfefferkorn, F.E.; Li, X.-C. Novel nanoprocessing route for bulk graphene nanoplatelets reinforced metal matrix nanocomposites. Scr. Mater. 2012, 67, 29-32. [CrossRef]

40. Liu, S.-Y.; Gao, F.-P.; Zhang, Q.-Y.; Zhu, X.; Li, W.-Z. Fabrication of carbon nanotubes reinforced AZ91D composites by ultrasonic processing. Trans. Nonferrous Met. Soc. China 2010, 20, 1222-1227. [CrossRef]

41. Mussi, R.G.S.; Motegi, T.; Tanabe, F.; Kawamura, H.; Anzai, K.; Shiba, D.; Suganuma, M. Effect of ultrasonic vibration on the dispersion of carbon nano-fibre reinforcement through semi-solid az91d magnesium alloy. Solid State Phenom. 2006, 116-117, 392-396. [CrossRef]

42. Nie, K.B.; Wang, X.J.; Xu, L.; Wu, K.; Hu, X.S.; Zheng, M.Y. Influence of extrusion temperature and process parameter on microstructures and tensile properties of a particulate reinforced magnesium matrix nanocomposite. Mater. Des. 2012, 36, 199-205. [CrossRef]

(C) 2018 by the author. Licensee MDPI, Basel, Switzerland. This article is an open access article distributed under the terms and conditions of the Creative Commons Attribution (CC BY) license (http:/ / creativecommons.org/licenses/by/4.0/). 